\title{
Molecular Cloning and Characterization of Attacin from the Swallowtail Butterfly, Papilio xuthus
}

\author{
Seong Ryul Kim, Jae Sam Hwang, Seung Won Park, Tae Won Goo, Iksoo Kim ${ }^{\mathbf{1}}$, and Seok Woo Kang* \\ Department of Agricultural Biology, National Academy of Agricultural Science, RDA, Suwon 441-100, Republic of Korea \\ ${ }^{1}$ Institute of Environmentally-Friendly Agriculture, College of Agriculture and Life science, Chonnam National University, \\ Gwangiu 500-757, Republic of Korea
}

(Received 04 October 2011; Accepted 22 November 2011)

\begin{abstract}
Attacin is an insect antibacterial protein that plays an important role in immune response to injury and infection. In this report, we have isolated and characterized of cDNA encoding for the attacin from the immunized larvae of swallowtail butterfly, Papilio xuthus. A full length cDNA of $P$. xuthus attacin was obtained by employing annealing control primer (ACP)-based differential display PCR and 5, RACE. The complete $P$. xuthus attacin cDNA was comprised of 949 bp encoding a 250 amino acid precursor. It contains a putative 18 amino acid signal peptide sequence, a 42 amino acid propeptide sequence, and a 190 amino acid mature protein with a theoretical molecular mass of 19904.01 and a $\mathrm{pI}$ of 9.13. The putative mature protein of $P$. xuthus attacin showed $48-52 \%$ and $24-30 \%$ identity in amino acid sequences with that of lepidopteran and dipteran insects, respectively. Semiquantitive RT-PCR results revealed that the transcript of $P$. xuthus attacin gene was up-regulated at significant levels after injection with bacterial lipopolysaccharide (LPS). We sub-cloned cDNA fragment encoding mature $P$. xuthus attacin into the expression vector, highly expressed in $E$. coli BL21 cells, and its antibacterial activity was analyzed. Recombinant $P$. xuthus attacin evidenced considerably antibacterial activity against Gram-negative bacteria, E. coli ML 35 and Klebsiella pneumonia.
\end{abstract}

Key words: Papilio xuthus, Attacin, Antibacterial protein, Expression, RT-PCR

\footnotetext{
*To whom the correspondence addressed

Department of Agricultural Biology, National Academy of Agricultural Science, RDA, Suwon 441-100, Korea.

Tel: +82-31-290-8536; Fax: +82-31-290-8530;

E-mail: kangsw@korea.kr
}

\section{Introduction}

Attacin, which is a well-studied glycine-rich antibacterial protein in lepidopteran insect immunity, was first isolated from the immune haemolymph of moth Hyalophora cecropia (Hultmark et al., 1983). This protein inhibits growth of Gram-negative bacteria, such as E. coli (Engstrom et al., 1984; Kishimoto et al., 2002). It is thought to acts toward Gram-negative bacteria out membrane causing permeability perturbations by interacting with lipopolysaccharides (LPS) and specifically inhibiting the synthesis of several out membrane protein (Carlsson et al., 1991, 1998). The $H$. cecropia attacin consist of two different form, one acidic (pI 7) and one basic (pI 9) protein with $80 \%$ primary sequence identity (Engstrom et al., 1984; Hultmark et al., 1983), and is found to be strongly induced by LPS and bacterial infection (Sun et al., 1991). Since two cDNAs encoding the acidic and basic attacin were cloned from $H$. cecropia (Kockum et al., 1984), many attacin genes have been identified from several lepidopteran and dipteran insects such as Bombyx mori (Sugiyama et al., 1995), Drosophila melanogest (Asling et al., 1995; Dushay et al., 2000), Trichoplusia ni (Kang et al., 1996), Hyphantria cunea (Kwon et al., 2008), eri-silkworm (Kishimoto et al., 2002) and Glossina morsitans (Wang et al., 2008). Furthermore, three attacin genes were also identified in coleopteran insect, Tribolium castaneum (Zou et al., 2007). Most of them are synthesized as a preproproteins with signal peptide and proprotein. Mature attacin without cystein residues typically being about 190 amino acids in length and form a random coli structure in solution (Gunne et al., 1990).

In the silkworm B. mori, six major antimicrobial peptides, cecropin, lebocin, moricin, attacin, defensin and gloverin, are produced by injection of bacteria, LPS and peptidoglycan (Kaneko et al., 2007; Kato et al., 1993; Tanaka et al., 2008). Furthermore, attacin gene expression 
is up-regulated by the injection of Escherichia coli and continued at least for 48 hours mainly in the larvae fat bodies and hemocytes (Sugiyama et al., 1995). In tsetse immune response, while attacin transcription is rapidly induced within hours by provisioning $E$. coli in an infected bloodmeal (Hao et al., 2006).

In order to a better understand the molecular bases of the host immune response to parasitoid attack and the regulation of the antibacterial protein gene expression in swallowtail butterfly Papilio xuthus, we have tried to cloned a basic attacin cDNA from swallowtail butterfly, $P$. xuthus. In the present study, we described the structural analysis of attacin gene and biological characterization of recombinant attacin that was expressed in E. coli.

\section{Materials and Methods}

\section{Insects and immunization}

The swallowtail butterfly Papilio xuthus was collected from the field. Larvae were reared on leaves of Amur cork tree (Phellodendron amurense Rupr.) at $25^{\circ} \mathrm{C}$ under longday conditions ( $16 \mathrm{hrs} \mathrm{light} \mathrm{/} 8$ hrs dark). Only final-instar larvae were used for infection. A volume of $20 \mu \mathrm{l}$ of lipopolysaccharide (LPS, sigma, $0.5 \mathrm{mg} / \mathrm{ml}$ ) dissolved in sterile insect Ringer was injected dorsolaterally into the hemocoel using $1 \mathrm{ml}$ disposable syringes.

\section{Annealing control primer (ACP)-based differential PCR}

Total RNA were extracted from whole larvae at $12 \mathrm{~h}$ postinjection or from untreated larvae using Trizol reagent (Invitrogen, CA) and then treated for 15 min with DNase I at $37^{\circ} \mathrm{C}$ to remove any residual genomic DNA. Total RNA were used for the synthesis of first-strand cDNA by reverse transcriptase. Reverse transcription was performed for $1.5 \mathrm{hrs}$ at $42^{\circ} \mathrm{C}$ in a final reaction volume of $20 \mu \mathrm{l}$ containing $3 \mu \mathrm{g}$ purified total RNA, $4 \mu \mathrm{l}$ of $5 \times$ reaction buffer (Promega, USA), $5 \mu$ of dNTPs (each $2 \mathrm{mM}$ ), $2 \mu \mathrm{l}$ of $10 \mu \mathrm{M}$ cDNA synthesis primer dT-ACP $1,0.5 \mu \mathrm{l}$ of RNasin“ RNase Inhibitor (40//U/ $\mu$; Promega, USA), and $1 \mu \mathrm{l}$ of M-MLV reverse transcriptase (200 U/ $\mu \mathrm{l}$; Promega, USA). First-strand cDNA samples were diluted by the addition of 80 il of ultra-purified water. For screening differentially expressed gene (DEG) in immune-challenged $P$. xuthus larvae, we used Annealing control primer (ACP)-based GeneFishing PCR kit (Seegene, Korea). Briefly, ACP-based PCR were conducted using 120 pairs of arbitrary ACPs and dT-ACP2 to synthesize the secondstrand cDNA. PCR analysis were performed in a final volume of $20 \mu \mathrm{l}$ containing $4 \mu \mathrm{l}$ of diluted first-strand cDNA, $1 \mu \mathrm{l}$ of dT-ACP2 $(10 \mu \mathrm{M}), 1 \mu \mathrm{l}$ of $10 \mu \mathrm{M}$ arbitrary ACP, and $10 \mu$ of $2 \times$ Master Mix (Seegene, Korea). The PCR protocol for second-strand synthesis was one cycle at $94^{\circ} \mathrm{C}$ for $1 \mathrm{~min}$, followed by $50^{\circ} \mathrm{C}$ for $3 \mathrm{~min}$, and $72^{\circ} \mathrm{C}$ for $1 \mathrm{~min}$. After second-strand DNA synthesis was completed, the second-stage PCR amplification protocol was 40 cycles of $94^{\circ} \mathrm{C}$ for $40 \mathrm{~s}$, followed by $65^{\circ} \mathrm{C}$ for $40 \mathrm{~s}$, $72^{\circ} \mathrm{C}$ for $40 \mathrm{~s}$, followed by a $5 \mathrm{~min}$ final extension at $72^{\circ} \mathrm{C}$. The amplified PCR products were separated in $2 \%$ agarose gel and stained with ethidium bromide. Differentially expressed bands were extracted and cloned into the pGEM-T easy vector (Promega, USA) and sequenced. Sequence data of DNA fragments were analyzed by BLAST search (http://www.ncbi.nlm.nih.gov).

\section{5'- RACE (rapid amplification of cDNA ends)}

To determine entire open reading frame (ORF) of DEG 9 fragment (540 bp) which confirmed to partial attacin gene, a 5'-RACE reaction was performed using an available kit (Invitrogen, USA) which resulted in the cloning of a fulllength cDNA. Two antisense primers (5'-CTGAGTAGTCGGTCTTCTTGAACA-3' and 5'-GTCG-TTGTGGAAGATGTTAGCCTT-3' as GSP1 and GSP2, respectively) were synthesized based on the confirmed DEG 9 sequence. First strand cDNA was synthesized using the gene specific primer (GSP1) from the immunized larvae total RNA. The addition of a polymeric $\mathrm{C}$ tail to first strand $\mathrm{CDNA}$, $\mathrm{PCR}$ amplification using GSP1 and an abridged anchor primer, and subsequent nested PCR amplification using GSP2 and abridged universal amplification primer, were done based on the manufacturer's protocol. The resulting PCR product (552 bp) was then sub-cloned into the pGEM-T easy vector (Promega, USA) and subjected to DNA sequencing. Homology search of completely $P$. xuthus attacin cDNA sequence was performed with the BLAST software on the NCBI (http:// www.ncbi.nlm.nih.gov).

\section{Reverse transcription PCR}

To analysis the transcription of $P$. xuthus attacin in immune-challenged larvae, total RNA was extracted from whole larvae $0 \mathrm{~h}, 12 \mathrm{~h}$ and $24 \mathrm{~h}$ post injection using Trizol reagent (Invitrogen, CA) and then treated for $15 \mathrm{~min}$ with DNase I. Treated RNA samples ( $1 \mu \mathrm{g}$ per sample) were used for cDNA synthesis with oligo (dT) primer and SuperScript III reverse transcriptase (Invitrogen, CA). PCR amplifications were performed using a pair of specific primers (5'-GCTTGGCTTGGGATAACATTAAGG-3' and 5'-CTGAGTAGTCGGTCTTCTTGAACA-3') under the following conditions: $94^{\circ} \mathrm{C}$ for $30 \mathrm{~s}, 62^{\circ} \mathrm{C}$ for $45 \mathrm{~s}$, and $72^{\circ} \mathrm{C}$ for $1 \mathrm{~min}$ for 25 cycles with final extension at $72^{\circ} \mathrm{C}$ for $10 \mathrm{~min}$. The amplified PCR products were electrophoresed through $1 \%$ agarose gel. The gene for the ribosomal protein L3 (rpL3, Futahashi and Fujiwara, 2006) was used as an internal control. 


\section{Construction of the expression vector}

A cDNA fragment encoding mature $P$. xuthus attacin was synthesized by PCR amplification with a pair of specific primers (5'-CGGATCCGAACCAAGCACATGGCAACATC-3' and 5'-CAAGCTTAGAAGAATCTGGTGAAAGAA-3') containing BamHI and HindIII restriction site (underlined nucleotides), respectively. Specific primers were designed based on the nucleotide sequence of cloned $P$. xuthus attacin. PCR product was inserted into a pGEM-T easy vector (Promega, USA). After digestion with BamHI and HindIII enzymes, the mature attacin was sub-cloned into a pET29 expression vector digested with the same enzyme. The constructed expression vector was denoted as pET29b-PxAtt and confirmed by restriction endonucleases digestion and DNA sequence analysis. The resulting plasmid was transformed into E. coli BL21 (DE3) competent cells for expression.

\section{Recombinant protein expression, purification and cleavage} A single colony of $E$. coli BL21 (DE3) cells transformed with the pET29b-PxAtt were cultured in LB medium containing $15 \mu \mathrm{g} / \mathrm{ml}$ kanamycin for overnight at $37^{\circ} \mathrm{C}$. The overnight culture of transformed colony were inoculated into $500 \mathrm{ml} \mathrm{LB}$ medium with the ratio of $5 \%(\mathrm{v} / \mathrm{v}$,$) and$ grown at $37^{\circ} \mathrm{C}$ with vigorous shaking until an optical density $\left(\mathrm{OD}_{600}\right)$ reached $0.5 \sim 0.6$. Then expression was induced by adding IPTG to a concentration of $0.4 \mathrm{mM}$ for $5 \mathrm{hrs}$ at $37^{\circ} \mathrm{C}$. The culture was centrifuged at $10,000 \mathrm{rpm}$ for $10 \mathrm{~min}$ and resuspended in BugBuster protein extraction reagent (Novagen, Germany) with benzonase nuclease (Novagen, Germany). Then cells were lysed by incubation on a rotating mixer for $20 \mathrm{~min}$ at room temperature. The fusion protein was purified using the S-Tag thrombin purification Kit (Novagen, Germany) according to the manufacturer instruction. The eluted fractions containing the fusion protein were applied to SDS-PAGE analysis, and dialyzed against distilled water. To release recombinant attacin from the fusion protein, thrombin digestion was performed in a reaction buffer $(50 \mathrm{mM}$ Tris- $\mathrm{HCl}, \mathrm{pH} 7.4$, $2 \mathrm{mM} \mathrm{CaCl}_{2}$, and $50 \mathrm{mM} \mathrm{NaCl}$ ) at $25^{\circ} \mathrm{C}$ for overnight, and then applied to Sephadex G-50 column. Finally, the separated recombinant attacin was concentrated using the Amicon ultrafiltration (Amicon Ultra-10K, Millipore) and determined by SDS-PAGE analysis. The purified attacin was subjected to N-terminal sequencing analysis by the automated Edman degradation method on a pulsed liquidphase sequencer (ABI 491, Applied Biosystems).

\section{Assay of antibacterial activity}

The antibacterial activity of recombinant attacin was examined against Gram-negative E. coli ML35 (ATCC 43827), Klebsiella pneumonia (KACC 11257) and Gram-positive Staphylococcus aureus (KACC 10768) by agar well diffu- sion assay (Lehrer et al., 1991). For the antibacterial assay, bacteria were grown overnight at $37^{\circ} \mathrm{C}$ in tryptic soy broth (TSB; Difco). The culture was diluted in fresh TSB to $\mathrm{OD}_{600}$ to 0.04 . Then $400 \mu \mathrm{l}$ of cells suspension was inoculated into $10 \mathrm{ml}$ of worm $\left(40\right.$ to $\left.50^{\circ} \mathrm{C}\right)$ citrate phosphate buffer $(9 \mathrm{mM}$ sodium phosphate, $1 \mathrm{mM}$ sodium citrate, $\mathrm{pH}$ 7.4) containing $1 \%$ low-electroendosmosis-type agarose (Sigma) and $0.03 \%$ TSB. The mixture containing approximately $4 \times 10^{6}$ bacteria was rapidly poured into sterile petri dish to form a uniform layer after which $3.5 \mathrm{~mm}$ diameter holes were punched in the set agarose and filled with $10 \mathrm{ul}$ of dilution series of test recombinant attacin. After allowing $3 \mathrm{~h}$ for diffusion of the samples, a $10 \mathrm{ml}$ of TSB medium contain $1 \%$ agar was overlaid and then incubated overnight at $37^{\circ} \mathrm{C}$. The activity of recombinant attacin was further measured by inhibitory zone. To stability of recombinant attacin to temperatures, $10 \mathrm{iM}$ attacin was treated with different temperatures $\left(37,55,75\right.$, and $\left.95^{\circ} \mathrm{C}\right)$ for $20 \mathrm{~min}$ and antibacterial activity was assessed as described above.

\section{Results}

cDNA cloning and sequencing of $P$. xuthus attacin To isolated immune-related genes from $P$. xuthus larvae, we previously screened genes with immune inducible

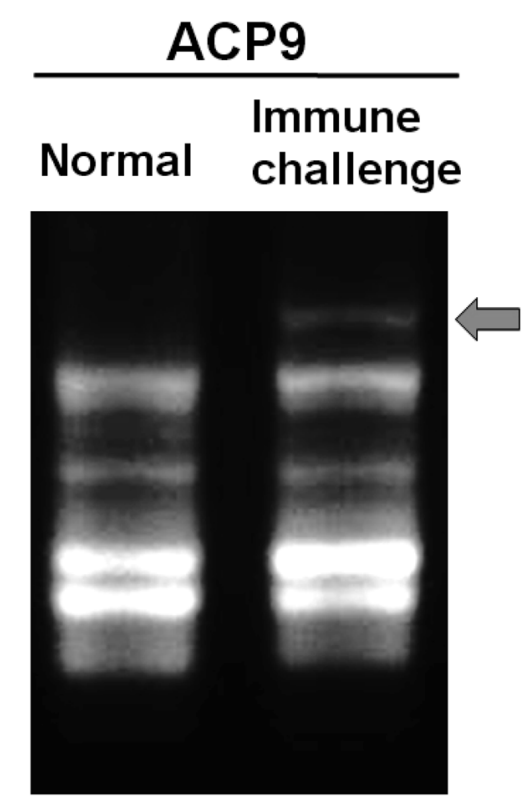

Fig. 1. Isolation of immune inducible gene from immune challenged P. xuthus. ACP9 products of ACP-based differential display PCR system from normal and immune challenged $P$. xuthus larvae were visualized via $2 \%$ agarose gel electrophoresis and ethidium bromide staining. Candidate attacin fragment was indicated with arrowheads. The size of product was about $540 \mathrm{bp}$. 
1 GCGGATCCAGACGCTGCGTTTGCTGGCTTTGATGAAAATCAGTTGCTTCGTTGACATCGA
61 AGAGTTCAGTAGAATAGCTTGTGTGAAGTAAAAGTTAATTAAAAACAAAAAATGTTCACA $M \quad F \quad T$

121 TCAAAAATCTTCGTCTTTGCGATGTTATTAATCAGCGTCAGCTGTAGATACTTAAATGAA $\begin{array}{lllllllllllllllllllll}S & K & I & F & V & F & A & M & \text { L } & \text { L } & \text { I } & \text { S } & \text { V } & \text { S } & \text { C } & \text { P R } & \text { Y } & \text { L } & \text { N } & \text { E }\end{array}$

181 GACCAAAGGCCGTATCTAGTCATTGAAGATGATGACAGCATTAGAATATTTGCTTTGGAA $\begin{array}{llllllllllllllllllll}D & Q & R & P & Y & L & V & I & E & D & D & D & S & I & R & I & F & A & L & E\end{array}$

241 GATGAAGCTGATGATGAAGTGGAAGAATTGCATCCAGTTAGAGTTAGAAGACAAGCACAT

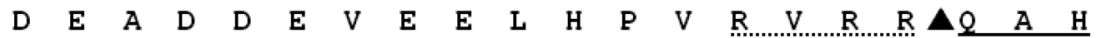

301 GGCAACATCAACACAAACCCAGATGGAAGTTCTAACGTTGCTGCGAAGATACCAATAGCC

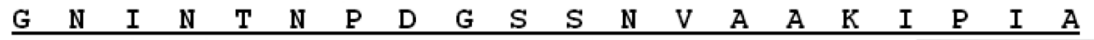

361 CGAGGTGACAGTAATGTTTTGAGCGCTATAGGTTCAGTTAATGCCGCTGACGGCAAGGGA \begin{tabular}{llllllllllllllllllll}
$\mathbf{R}$ & $G$ & $\mathbf{D}$ & $\mathbf{S}$ & $\mathbf{N}$ & $\mathrm{V}$ & $\mathrm{L}$ & $\mathbf{S}$ & $\mathrm{A}$ & $\mathrm{I}$ & $\mathrm{G}$ & $\mathbf{S}$ & $\mathrm{V}$ & $\mathrm{N}$ & $\mathrm{A}$ & $\mathrm{A}$ & $\mathrm{D}$ & $\mathrm{G}$ & $\mathrm{K}$ & $\mathrm{G}$ \\
\hline
\end{tabular}

421 GGATTCGGCTCAGCTGGTGCTGGCTTGGCTTGGGATAACATTAAGGGCCATGGAGCAACT $\begin{array}{llllllllllllllllllll}\text { G } & F & G & \text { S } & A & \text { G } & A & G & \text { L } & \text { A } & \text { W } & \text { D } & \text { N } & \text { I } & \text { K } & \text { G } & \text { H } & \text { G } & \text { A } & \text { T }\end{array}$

481 TTAACCGGTAGCCGCATCCCCGGTGTTGCCGATCAGCTGACTGCAAGCGGCAAGGCTAAC \begin{tabular}{llllllllllllllllllll}
$\mathrm{L}$ & $\mathrm{T}$ & $\mathrm{G}$ & $\mathrm{S}$ & $\mathrm{R}$ & $\mathrm{I}$ & $\mathrm{P}$ & $\mathrm{G}$ & $\mathrm{V}$ & $\mathrm{A}$ & $\mathrm{D}$ & $\mathrm{Q}$ & $\mathrm{L}$ & $\mathrm{T}$ & $\mathrm{A}$ & $\mathrm{S}$ & $\mathrm{G}$ & $\mathrm{K}$ & $\mathrm{A}$ & $\mathrm{N}$ \\
\hline
\end{tabular}

541 ATCTTCCACAACGACAAGCACGATCTCACCGCCAGTGCATTCGCCACAAGAACTTTCCCA \begin{tabular}{llllllllllllllllllll}
$\mathbf{I}$ & $\mathbf{F}$ & $\mathrm{H}$ & $\mathbf{N}$ & $\mathrm{D}$ & $\mathrm{K}$ & $\mathrm{H}$ & $\mathrm{D}$ & $\mathrm{L}$ & $\mathbf{T}$ & $\mathrm{A}$ & $\mathrm{S}$ & $\mathrm{A}$ & $\mathbf{F}$ & $\mathrm{A}$ & $\mathbf{T}$ & $\mathbf{R}$ & $\mathbf{T}$ & $\mathbf{F}$ & $\mathrm{P}$ \\
\hline
\end{tabular}

601 GACAAACCGAACTTCCCCACTTTCGATACTTATGGCGGAAAAGTTGGATACATGTACAAT \begin{tabular}{llllllllllllllllllll}
$\mathrm{D}$ & $\mathrm{K}$ & $\mathrm{P}$ & $\mathrm{N}$ & $\mathrm{F}$ & $\mathrm{P}$ & $\mathbf{T}$ & $\mathbf{F}$ & $\mathrm{D}$ & $\mathbf{T}$ & $\mathrm{Y}$ & $\mathrm{G}$ & $\mathrm{G}$ & $\mathrm{K}$ & $\mathrm{V}$ & $\mathrm{G}$ & $\mathrm{Y}$ & $\mathrm{M}$ & $\mathrm{Y}$ & $\mathrm{N}$ \\
\hline
\end{tabular}

661 GACAAGATCGGAGCAACCCTGGGAGCGGCACACACAGATCTGTTCAAGAAGACCGACTAC \begin{tabular}{llllllllllllllllllll}
$D$ & $\mathrm{~K}$ & $\mathrm{I}$ & $\mathrm{G}$ & $\mathrm{A}$ & $\mathrm{T}$ & $\mathrm{L}$ & $\mathrm{G}$ & $\mathrm{A}$ & $\mathrm{A}$ & $\mathrm{H}$ & $\mathrm{T}$ & $\mathrm{D}$ & $\mathrm{L}$ & $\mathbf{F}$ & $\mathrm{K}$ & $\mathrm{K}$ & $\mathrm{T}$ & $\mathrm{D}$ & $\mathrm{Y}$ \\
\hline
\end{tabular}

721 TCAGCAATGGGTAACCTAAACCTGTTCAAGGATCGCACCTCCTCCTTGGACTTGAACGCG $\begin{array}{llllllllllllllllllll}\mathbf{S} & \mathbf{A} & \mathbf{M} & \mathbf{G} & \mathbb{N} & \mathrm{L} & \mathbb{N} & \mathrm{L} & \mathbf{F} & \mathbf{K} & \mathbf{D} & \mathbf{R} & \mathbf{T} & \mathbf{S} & \mathbf{S} & \mathbf{L} & \mathbf{D} & \mathbf{L} & \mathbb{N} & \mathbf{A}\end{array}$

781 GGCTGGAGCAAGTCCGTCTCCCCTTACTTACCCAGCAATAGATGGGAGCCCAGTGGTGGT \begin{tabular}{llllllllllllllllllll}
$G$ & $W$ & $S$ & $K$ & $S$ & $V$ & $S$ & $P$ & $Y$ & L & $P$ & $S$ & $N$ & $R$ & $W$ & $E$ & $P$ & $S$ & $G$ & $G$ \\
\hline
\end{tabular}

841 ATTTCTTTCACCAGATTCTTCTAAGCAAGAAGACTAAAGTAATTAAGTGTTGTTTATTGT $\begin{array}{llllllll}I & S & F & T & R & F & F & *\end{array}$

901 AGATTTTTTGTA AATAAATAGATATGTAGTTAAAAAAAAAAAAAAAAAA

Fig. 2. Nucleotide and deduced amino acid sequences of the cDNA coding for P. xuthus attacin (GenBank accession no FJ438392). The putative mature protein sequence is underlined. ACP-based PCR product is highlighted in grey color. An Asterisk indicates the terminated codon. The solid arrow and closed triangle indicate the putative cleavage sites for the signal peptide and pro-peptide, respectively. Dashed line denotes the putative recognition site for enzyme cleavage. The polyadenylation signal (AATAAA) is boxed.

expression by annealing control primer (ACP)-based differential display PCR (Kim et al., 2010). Up-expressed genes in immune challenged larvae ACP-based PCR were conducted using 120 pairs of arbitrary ACPs and dTACP2 to synthesize the second-strand cDNA. By comparing the band intensities of amplified cDNA fragments between immune challenged larvae and non-immune larvae, we previously selected 26 DNA fragments with different expression levels. After analyzed nucleotide sequences, we performed homology searches of selected difference expressed genes (DEGs) using the BLAST program. The results show that one of these difference expressed genes (from DEG9 Fig. 1) had high similarity to carboxyl terminal region of attacin gene. The length of this cDNA fragment was $540 \mathrm{bp}$ including poly (A) tail (gray color highlighted from 410 bp to 949 bp in Fig. 2). Based on sequence of its fragment, specific primers were synthesized for 5'-RACE extension, which led eventually to the amplification of its full-length cDNA that consisted of 949 nucleotides with an open reading frame of 753 nucleotides encoding a putative preproprotein of 250 amino acid residues for $P$. xuthus attacin (Fig. 2, GenBank accession no. FJ438392). The sequence of its full-length cDNA also contained a 111 bp 5'-untranslated region and an $85 \mathrm{bp}$ 3'-untranslated region with a putative polyadenylation consensus signal (AATAAA). SignalP analysis revealed that the cleavage site for the potential signal peptide was predicted between 18-Cys and 19-Arg. A typical enzyme processing signal (RVRR) for pro-peptide was located at position 57 and 60 residues. Therefore, these results indicate that the putative mature $P$. xuthus attacin is consisted of 190 amino acids with predicted molecular mass of 19904.01 Da and isoelectric proint of 9.13 (Fig. 2).

\section{Sequence comparison}

BLAST analysis and sequence alignment of the deduced amino acid sequence of the mature $P$. xuthus attacin with other previously known insect attacin sequences were shown in Fig. 3A. The sequence comparison revealed that the newly isolated $P$. xuthus attacin shares $48-52 \%$ identity 
(A)
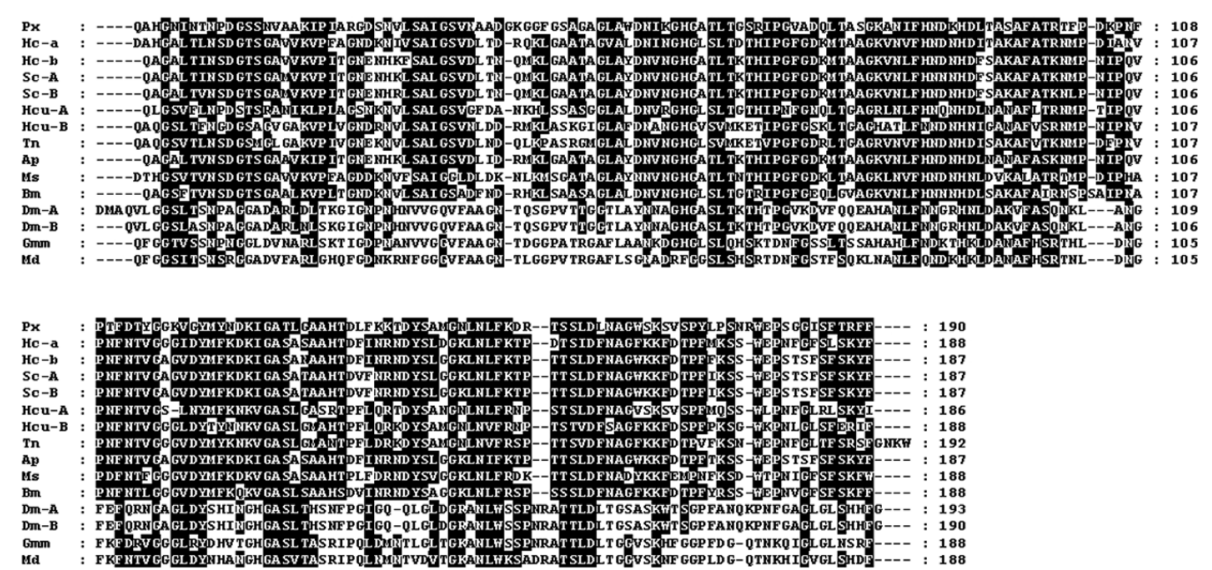

(B)

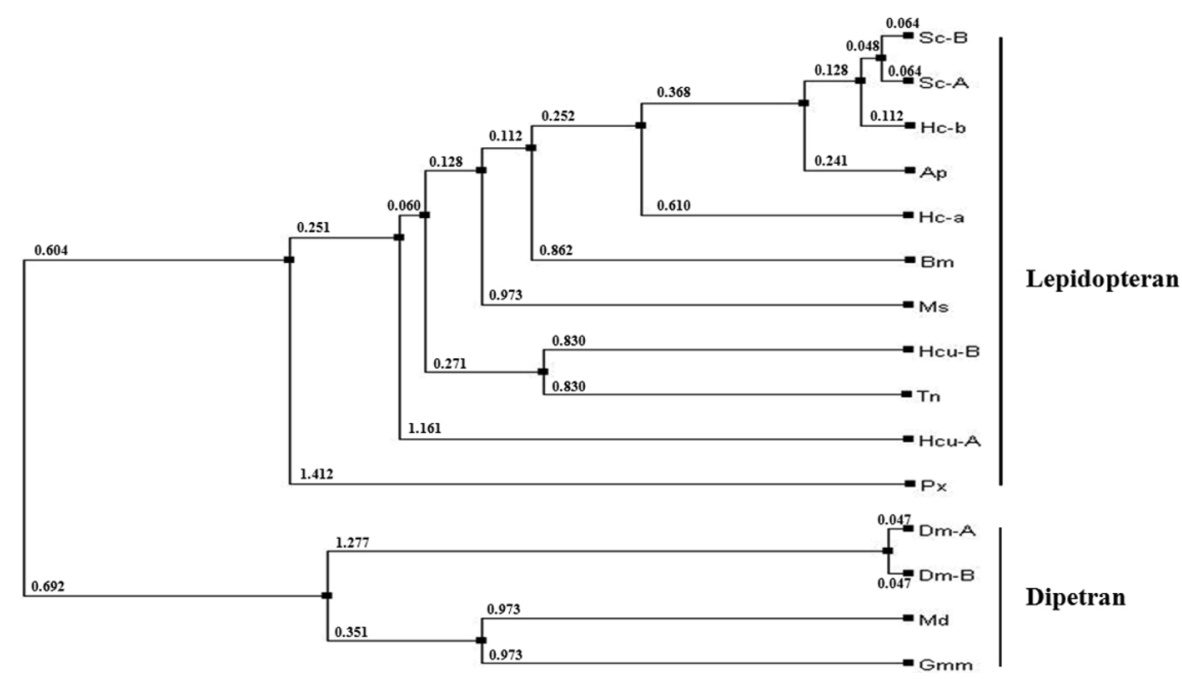

Fig. 3. Comparative sequence alignment and phylogenetic analysis of mature attacin proteins. (A) Multiple sequence alignment was performed using CLUSTALW program . Px, P. xuthus attacin; Hc-a, Hyalophora cecropia acidic attacin (M34926); Hc-b, H. cecropia basic attacin (X17619); Sc-A, Samia cynthia ricini attacin A (BAB69461); Sc-B, S. ricini attacin B (BAB69462); Hcu-A, Hyphantria cunea attacin A (AAD09288); Hcu-B, H. cunea attacin B (ABL63641); Tn, Trichoplusia ni attacin (AAC47327); Ap, Antheraea pernyi attacin (AAX58607); Ms, Manduca sexta attacin (AAY82587); Bm, Bombyx mori attacin (AAB34519); Dm-A, Drosophila melanogaster attacin A (AAF70455); Dm-B, D. melanogaster attacin B (AAL23663); Gm, Glossina morsitans morsitans attacin (AF368909); Musca domestica attacin (AAU08203). Conserved amino acids are highlighted. (B) Phylogenetic analysis was done by the neighbor-joining method for amino acid sequences among attacin proteins described above.

with other lepidopteran attacins, and $24-30 \%$ identity with the four dipteran attacins. To understand the evolutionary relationships among attacins, phylogenetic analysis of the available mature attacins was performed at the amino acid level (Fig. 3B). The phylogenetic result revealed that the mature attacins classified two rooted groups corresponding to the lepidopteran and dipteran attacins.

\section{Time course transcription of $\boldsymbol{P}$. xuthus attacin gene}

The transcription levels of $P$. xuthus attacin gene in the larvae after bacterial LPS challenge at different time-points were examined by Semi-quantitive RT-PCR analysis. As shown in Fig. 4, the signal was detected at extremely weak bend when the larvae were not immunized, but the transcript levels increased significantly after immunization. High level gene expression persisted up to $24 \mathrm{~h}$ after LPS injection. This result indicated that the $P$. xuthus attacin gene expression was induced rapidly after challenge.

\section{Expression and purification of $P$. xuthus attacin}

The DNA fragment encoding $P$. xuthus attacin mature protein was inserted into down-stream of thrombin cleavage site of a pET29 expression vector. Transformed BL21 (DE3) cells harboring this recombinant plasmid were cultured and induced with $0.4 \mathrm{mM}$ IPTG and analyzed for expression by SDS-PAGE (Fig. 5A). Upon IPTG induction, the target pro- 


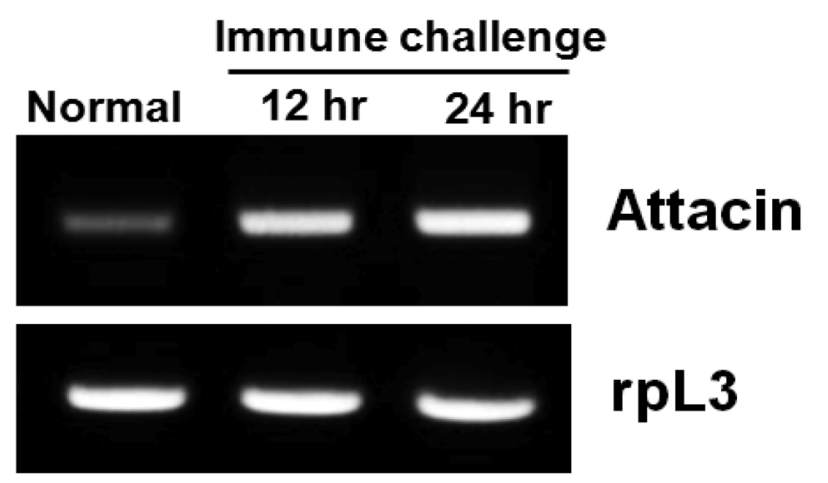

Fig. 4. RT-PCR analysis of $P$. xuthus attacin gene transcription in normal and the LPS-challenged larvae. The gene for the ribosomal protein L3 (rpL3) that is expressed constitutively in the cell was used as the control.

tein with N-terminal S-tag and attacin was predominantly expressed as soluble protein about $24 \mathrm{kDa}$. The recombinant fusion protein was easily purified by S-protein agarose resin affinity chromatography. The purified and desalted fusion protein was treated with thrombin to release attacin. The recombinant attacin was obtained by ultrafiltration using Amicon Ultra-10K centrifugal filter devices and a band about $20 \mathrm{kDa}$ was observed in SDS-PAGE (Fig. 5B).

\section{Antibacterial activity}

The antibacterial activity of recombinant $P$. xuthus attacin was examined by agar well diffusion assay (Fig. 6A). As we expected, the recombinant attacin showed highly antibacterial activity against two tested Gram-negative bacteria E. coli ML35 and Klebsiella pneumonia, lethal concentrations (LC) were 0.625 and $1.25 \mu \mathrm{M}$, respec-

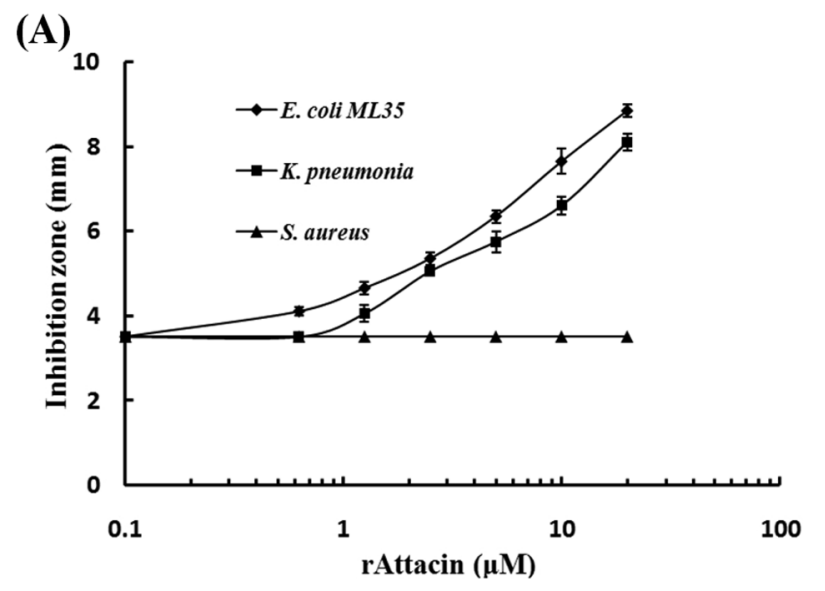

(B)

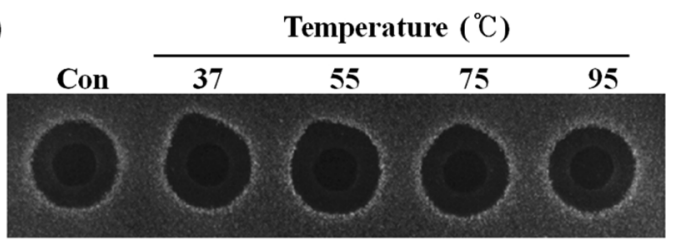

Fig. 6. Antibacterial activity and thermal stability of recombinant $P$. xuthus attacin. (A) The antibacterial activities of recombinant attacin against $E$. coli ML35 (diamonds), K. pneumonia (squares), and $S$. aureus (triangles) were tested at various concentrations (up to $20 \mu \mathrm{M}$ ). (B) Effect of temperature on recombinant attacin. $10 \mu \mathrm{M}$ attacin were treated with different temperatures $\left(37,55,75\right.$, and $\left.95^{\circ} \mathrm{C}\right)$. The sample kept at $4^{\circ} \mathrm{C}$ was used as a control.

tively. However, P. xuthus attacin did not inhibit the growth of Gram-positive bacteria Staphylococcus aureus. The thermal stability of recombinant $P$. xuthus attacin was tested under various incubation temperatures (Fig. 6B).
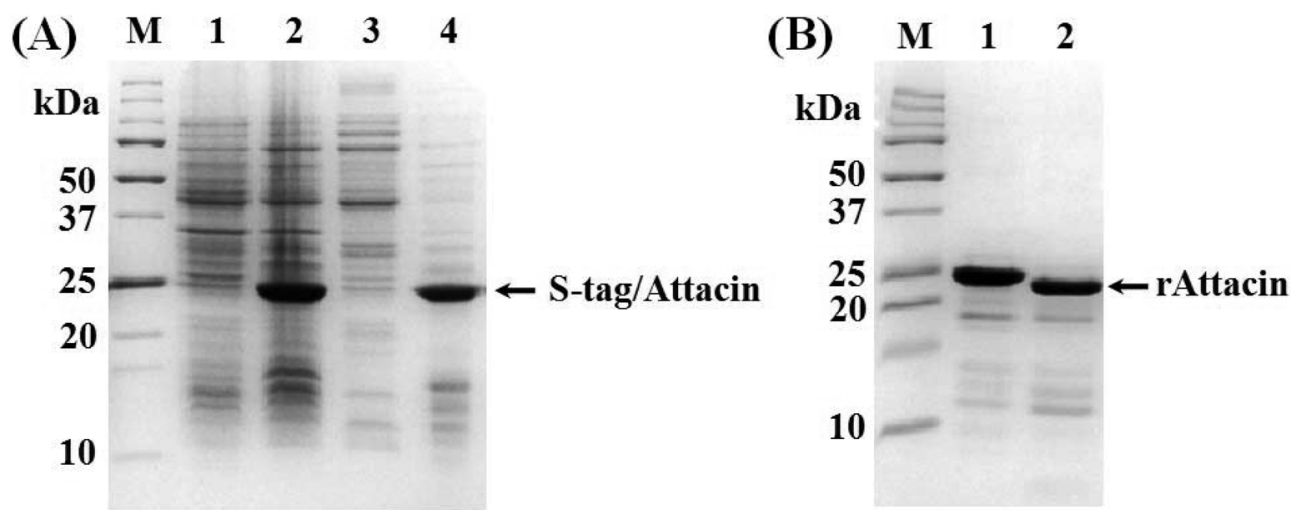

Fig. 5. Recombinant expression of P. xuthus attacin in E. coli. (A) Expression of fusion protein with N-terminal S-tag and attacin configuration in E. coli BL21(DE3). Lane M, protein molecular weight marker; Lanes 1 and 2, total bacterial proteins before and after IPTG induction, respectively; Lanes 3 and 4, insoluble and soluble fraction of induced cell extract, respectively. (B) Purification and cleavage of the fusion protein by thrombin. Lane M, protein molecular weight marker; Lane 1, partial purified fusion protein (S-tag/attacin); Lane 2, purified recombinant attacin cleaved by thrombin. 
The result of stability test showed that temperatures as high as $95^{\circ} \mathrm{C}$ for $20 \mathrm{~min}$ had no influence on the activity of recombinant $P$. xuthus attacin.

\section{Discussion}

The present study has cloned cDNA encoding attacin gene by employing annealing control primer (ACP)-based differential display PCR from the immune-challenged swallowtail butterfly, P. xuthus. The amino acid sequence of mature protein is highly similar to those attacin. $P$. xuthus attacin was expressed in E. coli BL21 (DE3), purified and analyzed its antibacterial activity. This is the first report of attacin gene in P. xuthus. Several attacin cDNAs have been cloned and characterized from lepidopteran and dipteran insects. This kind of protein usually consisted of a signal peptide, pro-peptide region that terminates with processing signal (RXRR), and the mature protein. A typical enzyme processing signal (RXRR) for pro-peptide was conserved among insect attacin genes (Kishimoto et al., 2002; Kwon et al., 2008). The attacin isolated from $P$. xuthus consisted of 250 amino acid residues. The sequence analysis suggested that the mature form starting with position 61 residues following to a conserved processing signal (RVRR), and consisting of 190 amino acids. Comparison of amino acid sequences of attacin indicates that the P. xuthus attacin has a high similarity to those of other lepidopteran insects, whereas relatively low similarity with dipteran insect attacin. The attacins isolated from immunized $H$. cecropia hemolymph were derived two type forms, acidic (pI 7) and basic (pI 9), with different isoelectric points (Engstrom et al., 1984). The pI value for $P$. xuthus attacin calculated from the amino acid sequence is 9.13 indicating it belongs to basic attacin form. The present results indicate that the P. xuthus attacin was successfully expressed as a recombinant protein in bacterial expression system. The purified recombinant attacin displayed high activity against Gram-negative bacteria such as $E$. coli, the aspect is similar to the activity of H. cecropia and eri-silkworm attacin (Engstrom et al., 1984; Kishimoto et al., 2002).

Our results strongly suggest that attacin plays an important role in the immune reaction against Gram-negative bacterial infection in P. xuthus. The identified attacin may further help to be applied in agriculture and medicine as new and safe antibiotics or bio-control agents.

\section{Acknowledgment}

This work was supported by a grant (No. 2009-
02FHT010102002) from Rural Development Administration, Republic of Korea

\section{References}

Asling B, Dushay MS, Hultmark D (1995) Identification of early genes in the Drosophila immune response by PCRbased differential display: the attacin A gene and the evolution of attacin-like proteins. Insect Biochem Mol Biol 25, 511-518.

Carlsson A, Engstrom P, Palva ET, Bennich H (1991) Attacin, an antibacterial protein from Hyalophora cecropia, inhibits synthesis of outer membrane proteins in Escherichia coli by interfering with omp gene transcription. Infect Immun 59, 3040-3045.

Carlsson A, Nystrom T, Cock DH, Bennich H (1998) Attacinan insect immune protein-binds LPS and triggers the specific inhibition of bacterial outer-membrane synthesis. Microbiol 144, 2179-2188.

Dushay MS, Roethele JB, Chaverri JM, Dulek DE, Syed SK, Kitami T (2000) Two attacin antibacterial genes of Drosophila melanogaster. Gene 246, 49-57.

Engstram P, Carlsson A, Engstrum A, Tao Z, Bennich H (1984) The antibacterial effect of attacins from the silk moth Hyalophora cecropia is directed against the outer membrane of Escherichia coli. EMBO J 3, 3347-3351.

Gunne H, Hellers M, Steiner H (1990) Structure of pre-proattacin and its processing in insect cells infected with a recombinant baculovirus. Eur J Biochem 187, 699-703.

Hao Z, Kasumba I, Lehane MJ, Gibson WC, Kwon J, Aksoy S (2001) Tsetse immune responses and trypanosome transmission: implications for the development of tsetse-based strategies to reduce trypanosomiasis. Proc Natl Acad Sci USA 98, 12648-12653.

Hultmark D, Engstrom A, Andersson K, Steiner H, Bennich H, Boman HG (1983) Insect immunity. Attacins, a family of antibacterial proteins from Hyalophora cecropia. EMBO J 2, 571-576.

Kaneko Y, Furukawa S, Tanaka H, Yamakawa M (2007) Expression of antimicrobial peptide genes encoding Enbocin and Gloverin isoforms in the silkworm, Bombyx mori. Biosci Biotechnol Biochem 71, 2233-2241.

Kang DW, Lundstrom A, Steiner H (1996) Trichoplusia ni attacin A, a differentially displayed insect coding for an antibacterial protein. Gene 174, 245-249.

Kato Y, Taniai K, Hirochika H, Yamakawa M (1993) Expression and characterization of cDNAs for cecropin $\mathrm{B}$, an antibacterial protein of the silkworm, Bombyx mori. Insect Biochem Mol Biol 23, 285-290.

Kim SR, Hong MY, Park SW, Choi KH, Yun EY, Goo TW, Kang SW, Suh HJ, Kim I, Hwang JS (2010) Characterization and cDNA cloning of cecropin-like antimicrobial peptide, Papiliocin from the swallowtail butterfly, Papilio xuthus. Mol Cells 29, 419-423. 
Kishimoto K, Fujimoto S, Matsumoto K, Yamano Y, Morishima I (2002) Protein purification, cDNA cloning and gene expression of attacin, an antibacterial protein, from eri-silkworm, Samia cynthia ricini. Insect Biochem Mol Biol 32, 881-887.

Kockum K, Faye I, Van Hofsten P, Lee JY, Xanthopoulos KG, Boman HG (1984) Insect immunity. Isolation and sequence of two cDNA clones corresponding to acidic and basic attacins from Hyalophora cecropia. EMBO J 3, 2071-2075.

Kwon YM, Kim HJ, Kim YI, Kang YJ, Lee IH, Jin BR, Han YS, Cheon HM, Ha NG, Seo SJ (2008) Comparative analysis of two attacin genes from Hyphantria cunea. Comp Biochem Physiol B Biochem Mol Biol 151, 213-220.

Sugiyama M, Kuniyoshi H, Kotani E, Taniai K, KadonoOkuda K, Kato Y, Yamamoto M, Shimabukuro M, Chowdhury S, Xu J, Choi SK, Kataoka H, Suzuki A, Yamakawa M (1995) Characterization of a Bombyx mori cDNA encoding a novel member of the Attacin family of insect antibacterial proteins. Insect Biochem Mol Biol 25,
385-392.

Sun SC, Lindstrom I, Lee JY, Faye I (1991) Structure and expression of the Attacin genes in Hyalophora cecropia. Eur J Biochem 196, 247-254.

Tanaka H, Ishibashi J, Fujita K, Nakajima Y, Sagisaka A, Tomimoto K, Suzuki N, Yoshiyama M, Kaneko Y, Iwasaki T, Sunagawa T, Yamaji K, Asaoka A, Mita K, Yamakawa M (2008) A genome-wide analysis of genes and gene families involved in innate immunity of Bombyx mori. Insect Biochem Mol Biol 38, 1087-1110.

Wang J, Hu C, Wu Y, Stuart A, Amemiya C, Berriman M, Toyoda A, Hattori M, Aksoy S (2008) Characterization of the antimicrobial peptide attacin loci from Glossina morsitans. Insect Mol Biol 17, 293-302.

Zou Z, Evans JD, Lu Z, Zhao P, Williams M, Sumathipala N, Hetru C, Hultmark D, Jiang H (2007) Comparative genomic analysis of the Tribolium immune system. Genome Biol 8, R177. 